\title{
Effects of experimental periodontitis on proliferation and osteogenic differentiation of adipose-derived stem cells in rats
}

\section{Yan Li Huang}

Sichuan University West China College of Stomatology

\section{Le Da Cheng}

Zhengzhou University

\section{Ya Jie Fan}

Xinxiang Medical University

Yi Wang

Xinxiang Medical University

\section{Baoyu Zhu}

Zhengzhou University First Affiliated Hospital

Rui Li ( $D$ liruisichuan@163.com )

\section{Research article}

Keywords: Effects of experimental periodontitis, proliferation and osteogenic differentiation of adiposederived stem

Posted Date: December 13th, 2019

DOI: https://doi.org/10.21203/rs.2.18744/v1

License: (c) (1) This work is licensed under a Creative Commons Attribution 4.0 International License. Read Full License 


\section{Abstract}

Background and Objective: The application of ASCs in periodontal regeneration is a good choice. Inflammatory micro-environment influenced the proliferation, mobilization, and osteogenic differentiation of ASCs in vitro.The aim of this study was to evaluate the effects of experiment periodontitis on the proliferation, wound healing and osteogenesis markers of adipose-derived stem cells (ASCs) in rats.

Materials and methods: Ten male rats were divided into two groups randomly. The control (Con) group received a standard diet, and the periodontitis (Peri) group was received a standard diet with placing ligatures around the maxillary first molar. Toll like receptor 4 (TLR4), Tumor necrosis factor-a (TNF-a) and Interleukin-1 $\beta$ (IL-1 $\beta$ ) were tested by immunohistochemistry (IHC) staining and quantitative real-time polymerase chain reaction (qRT-PCR). The proliferation rate of ASCs was measured through Cell Counting Kit-8 (CCK-8) assay. The migration speed of stem cells was evaluated by using a wound healing assay. The expression of alkaline phosphatase (ALP), bone morphogenetic protein-2 (BMP2) and runt related transcription factor 2 (Runx2) was evaluated by qRT-PCR analysis and western blot. Graph Pad Primer 7.0 software was used for statistical analysis.

Results: After 4 weeks, periodontitis model was successfully constructed. The results of IHC and RT-PCR found that in the Peri group, the TNF-a and IL-1 $\beta$ levels of adipose tissues decreased compared with the Con group $(P<0.05)$. The proliferation of Peri-ASCs significantly increased compared with Con-ASCs. Moreover, the wound healing ability of Peri-ASCs gradually increased in a time dependent manner compared with Con-ASCs. Results of RT-PCR showed that ALP and BMP2 gene levels of Peri-ASCs significantly decreased $(P<0.05)$, while the Runx2 gene level in Peri-ASCs was increased, when compared to Con-ASCs. The ALP activity of Peri-ASCs was decreased compared to the Con-ASCs, especially the difference was significant at day 5 day $(P<0.01)$. Western blot results showed that ALP, Runx2 and BMP2 protein levels of Peri-ASCs were significantly lower than those in Con-ASCs after osteogenic induction.

Conclusion: Our study demonstrated that experiment periodontitis decreased the expression of TNF-a and IL-1 $\beta$ in adipose tissue in rats. Experiment periodontitis promoted the proliferation and wound-healing ability of ASCs, but obviously inhibited the osteogenic differentiation of ASCs.

\section{Introduction}

Periodontitis is a chronic infectious disease and finally resulting in the loose or loss of tooth [1]. The ideal method of periodontitis therapy is to reconstruct the lost periodontal tissues, includes alveolar bone, periodontal ligament and cementum. A clinic trial proved that the long-period benefits of periodontal regeneration were better than flap [2]. Stem cells play an important role in cells based regenerative medicine [3, 4]. Some stem cells have been successfully applied in periodontal regeneration, such as periodontal ligament, dental follicle, bone marrow, and adipose tissue [5-7]. The biology characteristics of cells deprived of adipose tissue was influenced by physiological and pathological conditions [8]. ASCs are deprived from adipose tissue and contributing to tissue or cells renewal and repair $[9,10]$. As we know, 
ASCs have potential abilities to differentiate towards different cell lineages, such as osteoblast, chondrocyte and adipocyte $[11,12]$. ASCs can be deprived in large number. So, more and more studies focus the effects of inflammation on ASCs in vivo and vitro $[13,14]$. In appropriate conditions, the application of ASCs successfully repaired damaged periodontal tissues in animals $[15,16]$. These results suggest that ASCs is a good choice to be used in periodontal regeneration.

Previous research has found that inflammatory cytokines expressions in the adipose tissue in obese rats with periodontitis were higher than those in obese rats without periodontitis [17]. Other study demonstrated that inflammatory factor TNF-a increased the proliferation, mobilization, and osteogenic differentiation of ASCs in vitro [18]. So far, mostly previous study only explored the effects of inflammatory cytokines on proliferation and differentiation of ASCs in vitro. At present, there was no study to explore the influence of experiment periodontitis on the biological characters of ASCs in rats. The aim of this study was to preliminary explore the effects of experiment periodontitis on proliferation, would-healing, and osteogenic differentiation of ASCs in rats.

\section{Materials And Methods}

\section{Animals and experiment design}

SD rats were purchased from the experimental Animal Laboratory of Henan province (SCXK2007-0001). Ten, 8-week old, male SD rats completed this study. Each cage accommodated 3 to 4 rats. The condition was control temperature $\left(22 \pm 2^{\circ} \mathrm{C}\right)$ and light $(12: 12 \mathrm{~h}$ light-dark cycle).

These SD rats were divided into the Con group and Peri group randomly. The Con group just received a standard diet, and the Peri group received standard diet with placing ligatures around the maxillary first molar as described previously [19]. After 4 weeks, these ligatures were removed, and all rats were executed under general anesthesia.

\section{Alveolar bone analysis}

After the soft tissue was removed, the maxillae samples were performed as described previously [20].

Alveolar bone loss was measured (in $\mathrm{mm}$ ) from the cement-enamel junction (CEJ) to the alveolar bone crest (ABC) for each molar [21].

\section{Immunohistochemistry}

These adipose tissues were fixed in $4 \%$ paraformaldehyde for $48 \mathrm{~h}$ at $4^{\circ} \mathrm{C}$. Then they were dehydrated in an ascending series of ethanol solution and finally embedded in paraffin. For IHC analysis, slices were incubated with some primary antibodies, including mouse monoclonal anti-TLR4 antibody (Abcam), mouse monoclonal anti-TNF-a (Abcam) and rabbit monoclonal anti-IL-1 $\beta$ (Abcam). The immune reaction was observed and recorded using a light microscope (Olympus). 


\section{ASCs preparation}

Stem cells were collected from the adipose tissue in superficial abdominal region of rats and maintained in low glucose dulbecoo's modifified eagle's medium (DMEM, Hyclone) containing $10 \%$ fetal bovine serum (FBS, Hyclone), $100 \mu / \mathrm{ml}$ penicillin (Hyclone) and $100 \mathrm{mg} / \mathrm{ml}$ streptomycin (Hyclone). The primary ASCs were cultured for about 7-10 days and then passaged in 2-3 days. The third passage of ASCs was used for immunofluorescence staining and flow cytometry. The characteristics of membrane receptor phenotyping and differentiation assays were used to identify ASCs as reported previously [22]. The markers of ASCs were detected through flow cytometric analysis for CD90 FITC; CD105Percp-CY5.5, CD73 APC, CD31 PE, CD33 PE, CD3 PE (Biosciences). These differentiation abilities of ASCs were assessed by using osteogenesis and adipogenesis inducition. Osteogenic differentiation culture medium was made by low glucose d-MEM medium supplemented with $0.1 \mu \mathrm{M}$ dexamethasone (Sigma), 50 $\mu \mathrm{M}$ ascorbic acid (Sigma), $5 \mathrm{mM}$ ß-glycerophosphate (Sigma) for 4 weeks and finally using Alizarin Red staining to detect the osteocyte calcium deposit. Adipogenic differentiation culture medium was made by high glucose d-MEM medium supplemented with $1 \mu \mathrm{M}$ dexamethasone (Sigma), $0.5 \mathrm{M}$ misobutylmethylxanthine (Sigma), $10 \mu \mathrm{g} / \mathrm{ml}$ insulin (Sigma), and $100 \mu \mathrm{M}$ indomethacin (Sigma) for 2 weeks, and then determines the adipocyte lipid through Oil Red staining.

\section{CCK-8 Cell Viability Assay}

CCK-8 kit (Beyotime) was used to measure ASC's proliferation according to manufacturer's instructions. To analyze the growth kinetics of ASCs, cells were seeded into 96-well plates (Corning) at a density of $2.5 \times 10^{3}$ cells/

well. Each well was added 10 ul solution of CCK-8. Plates were incubated in $37^{\circ} \mathrm{C}, 5 \% \mathrm{CO} 2$ condition for 2 h. The absorbance values of each well were measured at $470 \mathrm{~nm}$.

\section{Wound healing assay}

Cells were seeded at a concentration of $1 \times 10^{5}$ cells per well in 6 -well plates. The culture medium was removed after 18 hours, and a wound was made in the center of each well by scratching with a $200 \mu \mathrm{l}$ pipette tip. Then, cells were washed twice with PBS and cultured with $2.5 \%$ FBS. Scratch wounds were imaged using an inverted microscope (Nikon) at beginning, $24 \mathrm{~h}, 72 \mathrm{~h}$, and $120 \mathrm{~h}$ post-wounding. The average wound widths were analyzed using Image Pro Plus 6.0 software as previously [23].

\section{Alkaline phosphatase activity}

ALP activity was measured using ALP assay kit (NanjingJiancheng Bioengineering Institute) according to the manufacturer's protocols. To evaluate osteogenic differentiation of these stem cells, cells were seeded into 24-well plates (Costar) at a concentration of $1 \times 10^{4}$ cells/well, and then incubated in the osteogenesis medium. All data were normalized to total protein content. More than three parallel replicates were analyzed in each group. 


\section{Quantitative real-time polymerase chain reaction (qRT-PCR)}

Total RNA was extracted using Trizol Reagent kit (Invitrogen) according to the manufacturer's protocol followed by cDNA synthesis and PCR procedures. Quantitative PCR program was set at $94^{\circ} \mathrm{C}$ for $30 \mathrm{~s} ; 40$ cycles of $95^{\circ} \mathrm{C}$ for $5 \mathrm{~s}, 60^{\circ} \mathrm{C}$ for $30 \mathrm{~s}$, and $95^{\circ} \mathrm{C}$ for $15 \mathrm{~s}$; followed by $60^{\circ} \mathrm{C}$ for 1 min. Relative gene level was calculated using the 2- $\triangle \Delta C T$ method and normalized to GAPDH gene. The primers were designed and synthesized by a company (Sangon Biotechnology Co.). Sequences of target primers used are showed in Table 1.

\section{Western blot}

The total of cells proteins was dissolved in RIPA Lysis Buffer (Servicebio) containing PMSF (Servicebio) in $30^{\circ} \mathrm{C}$ for $30 \mathrm{~min}$ and finally centrifuged at $12000 \mathrm{rpm}$ at $4^{\circ} \mathrm{C}$ for $10 \mathrm{~min}$. The concentration of protein was measured by BCA protein kit (Servicebio) according to instructions. Proteins were transferred to a PVDF membrane (Millipore) for 1 hour at $200 \mathrm{~mA}$. The membranes were incubated in $5 \%$ skim milk for 2 $\mathrm{h}$. Then, the membrane was incubated with primary antibody at $4^{\circ} \mathrm{C}$ for $3 \mathrm{~h}$. These primary antibodies as follows: ALP (1:3000, Abcam), BMP2 (1:3000, Abcam), Runx2 (1:3000, Abcam), GAPDH (1:5000, Zhengneng) serves as the internal control in these experiments. Assays were repeated three times and the gray value of western blot stripe was measured by Image $\mathrm{J}$.

\section{Satatistical analysis}

All data were expressed as mean \pm standard error of the mean (SEM) and $95 \%$ confidence intervals. All data were analyzed via t-test. Statistical analysis was performed using Graph Pad Primer 7.0. The value of differences $\mathrm{P}<0.05$ was considered statistically significant.

\section{Results}

\section{Experiment periodontitis inhibited the TNF-Iand IL-1 $\beta$ expressions in the adipose tissue}

The bone loss of the first maxillary molar in the Peri group was more than that in the Con group $(P<0.01$; Fig. 1A). IHC staining for TNF- $\alpha$ and IL-1 $\beta$ were both positive in the adipose tissue in the Con group and Peri group, but TLR4 of adipose tissue was negative in this two groups. The fluorescence intensity of TNF- $\alpha$ and IL-1 $\beta$ were higher in the Con group than in the Peri group (Fig. 1B). RT-PCR results showed there are significant decrease in the expression of TNF- $\alpha(P<0.001$; Fig. $1 \mathrm{C})$ and IL-1 $\beta(P<0.05$; Fig. 1C) in the Peri group compared with the Con group. There was no significant difference in TLR4 gene expression in the two groups.

\section{ASCs characterization}

ASCs showed the shape morphology at the third in vitro passage (Fig. 2A). Flow cytometric analysis showed that the ASCs positively expressed the differentiation potential markers CD29 and CD73. The lack of receptors for CD90, CD31 and CD34 suggested that ASCs did not have haematopoietic and 
angiogenesis lineages (Fig. 2B). ASCs were positive for the mesenchymal marker Vimentin (Fig. 2C), but negative for CK-14 (Fig. 2D), which is a marker of epithelial cells. Lipid droplets formed and were stained with oil red (Fig. 2E). When cultured in osteogenic medium for 4 weeks, calcified nodule was stained with alizarin red staining (Fig. 2F).

\section{The proliferation and wound-healing capability of ASCs}

In order to measure the proliferation and the migration of ASCs, CCK-8 cell assay and wound healing assay were performed. As illustrated in cell growth cure (Fig. 3A), the average OD value of Peri-ASCs significantly increased compared with the value of Con-ASCs. Cell migration speed was determined by measuring the diameters of wounded spaces on 6-well plates. After 1-day simulation, the migration speed of Peri-ASCs was significantly slower than Con-ASCs ( $P<0.001$; Fig. $3 C$ ). But the migration speed of PeriASCs gradually increased compared with Con-ASCs after 3-day and 5-day induction ( $P<0.001$; Fig. 3C).

\section{The expression of ALP, Runx2 and BMP2 gene and ALP activity of ASCs}

RT-PCR results demonstrated that ALP and BMP2 gene expressions in the Peri-ASCs group significantly decreased compared with the Con-ASCs group after 3-day, 5-day and 7-day induction, respectively (Fig. $4 A, C)$. However, the difference of the two groups gradually reduced. However, the Runx2 gene expression significantly increased in the Peri-ASCs group compared with the Con-ASCs group at 3-day (Fig. 4B; $P<0.01$ ) and 5-day (Fig. 4B; $P<0.001$ ). While, the difference of ALP, Runx2 and BMP2 gene expression between the two groups gradually decreased. After osteogenic induction for 3-day, 5-day and 7-day, the ALP activities of cells in different groups were measured. These results showed that the ALP activity of Peri-ASCs decreased compared to the Con-ASCs, especially on 5-day (Fig. 4D; $P<0.01$ ).

\section{The expression of ALP, Runx2 and BMP2 protein in two groups after osteogenic induction}

Western blot results showed that the ALP protein levels of Peri-ASCs significantly decreased compared to Con-ASCs, after 3-day and 5-day simulation. After 7-day simulation, the ALP protein expression of PeriASCs was increased compared to Con-ASCs. The Runx2 and BMP2 protein levels of Peri-ASCs also decreased compared with the Con-ASCs after 3-day, 5-day and 7-day simulation, there were significance (Fig. 5).

\section{Discussion}

In this study, we preliminary investigated the effect of experiment periodontitis on the proliferation, wound healing ability and osteogenic differentiation of ASCs in rats. Firstly, we successfully constructed experiment periodontitis model in rats. As we know, there are bidirectional association between periodontal disease and metabolic diseases, such as obesity/overweight, prediabetes and diabetes [2426]. Clinical study found that serum levels of inflammatory cytokines such as TNF- $\alpha$ and IL-1 $\beta$ in patients with periodontitis were higher than healthy person [27]. TNF- $\alpha$ and IL-1 $\beta$, expressed in and secreted by adipose tissue, play an important role in the progression of periodontal diseases and other chronic 
diseases [28-30]. Our data showed that the TNF-a and IL-1 $\beta$ levels in the adipose tissue were significantly lower in rats with periodontitis than normal rats. Experiment periodontitis inhibited the TNF-a and IL-1 $\beta$ expressions in the adipose tissue in rats. These results showed that periodontitis inhibited the TNF-a and IL-1 $\beta$ levels of abdominal adipose tissue at the early phase in rats.

As we know, ASCs have been applied in periodontal regeneration, bone regeneration and wound repair [31-33]. In this study, the proliferation rate and migration speed of Peri-ASCs significantly increased compared with Con-ASCs. Previous study showed the conditioned medium of ASC-sheets stimulated with low concentration of TNF- $\$ enhanced endothelial cell proliferation and fibroblast migration [34]. The proliferation and migration of stem cells are very important in repairing lost tissues and wound healing. In

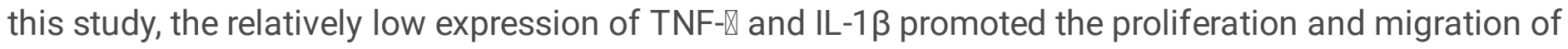
ASCs in rats.

Some evidences demonstrated that the differentiation potential of MSCs in an inflammatory microenvironment was decreased [35-37]. The osteogenic differentiation of PDLSCs in inflammatory condition was significantly decreased [38]. ALP usually was detected to inflect the osteogenesis potential [39]. In this study, the ALP gene and protein levels were inhibited by periodontitis in rats. In addition, the ALP activity of ASCs was impaired in experimental periodontitis condition. Runx2 is related with osteogenesis [40]. This study found that Runx2 gene and protein expressions decreased in Peri-ASCs compared with Con-ASCs after osteogenesis induction. BMP-2 is an important differentiation factor that is capable of inducing bone regeneration [41]. In this study, the BMP2 gene and protein levels in Peri-ASCs significantly decreased compared with the Con-ASCs. These results demonstrated that experiment periodontitis inhibited the osteogenic differentiation of ASCs in rats. Although the proliferation and migration of Peri-ASCs were enhanced compared with Con-ASCs, the osteogenic differentiation of PeriASCs was weaker than Con-ASCs. In the future, we hope that patients with chronic periodontitis may be treated through autologous cells-based tissue regeneration.

\section{Conclusions}

Sum up, this study demonstrated that the proliferation and wound-healing ability of rat ASCs were promoted by experiment periodontitis, but the osteogenic differentiation of rat ASCs was inhibited. However, it is still not clear how periodontitis influences the biology character of ASCs. The future research is needed to further define the underlying mechanism.

\section{Abbreviations}

ASCs: Adipose-derived stem cells; Con: Control; Peri: Periodontitis; TLR4: Toll like receptor 4; TNF-a: Tumor necrosis factor-a; IL-1 $\beta$ : Interleukin-1 $\beta$; IHC: Immunohistochemistry; qRT-PCR: Quantitative real-time polymerase chain reaction; CCK-8: Cell Counting Kit-8; ALP: Alkaline phosphatase; BMP2: Bone morphogenetic protein-2; Runx2: Runt related transcription factor 2; CEJ: Cement-enamel junction; ABC: Alveolar bone crest 


\section{Declarations}

\section{Funding}

This current study was supported by Natural Science Foundation of China (31670994), Natural Science Foundation of Henan Province (182300410340), and Medical Science and Technology Project (2018020382). Department of Stomatology, The First Affiliated Hospital of Zhengzhou University, No1, Eastern Jianshe Road, Erqi District, Zhengzhou, Henan Province, China.

\section{Availability of data and materials}

The datasets used for the current study are available from the corresponding author by request.

\section{Authors' contributions}

Rui Li and Baoyu Zhu designed and directed the experiments, and revised the whole manuscript thoroughly. Yanli Huang and Leda Cheng performed most of the experiments and wrote the manuscript. Yajie Fan participated in some of the experiments and wrote part of the manuscript. Yi Wang performed the analysis for all of the results and revised the whole manuscript. All authors have given final approval of this version to be published. All authors read and approved the final manuscript.

\section{Ethics approval and consent to participate}

The present study was approved by the Ethics Committee of First Affiliated Hospital of Zhengzhou University, China.

\section{Consent for publication}

Not applicable.

\section{Competing interests}

All authors state that there is no conflict of interests regarding this paper's publication.

\section{References}

1. Pihlstrom BL, Michalowicz BS, Johnson NW. Periodontal diseases. Lancet.2005; 366:1809-20. 2. Cortellini P, Buti J, Pini Prato G, Tonetti MS. Periodontal regeneration compared with access flap surgery in human intra-bony defects 20-year follow-up of a randomized clinical trial: tooth retention, periodontitis recurrence and costs. J Clin Periodontol. 2017; 44:58-66. 3. Ankrum, J, and Karp, J.M. Mesenchymal stem cell therapy: Two steps forward, one step back. Trends Mol Med. 2010;16: 203-9. 4. Pittenger MF, Mackay AM, Beck SC, Jaiswal RK, Douglas R, Mosca JD, et al. Multilineage potential of adult human mesenchymal stem cells. Science.1999; 284:143-7. 5. Guo S, Kang J, Ji B, Guo W, Ding Y, Wu Y, et al. Periodontal-derived mesenchymal cell sheets promote periodontal regeneration in inflammatory 
microenvironment. Tissue Eng Part A. 2017; 23:585-96. 6. Zhou Q, Gu X, Dong J, Zhu C, Cai Z, He D, et al. The use of TLR2 modified BMSCs for enhanced bone regeneration in the inflammatory microenvironment. Artif Cells Nanomed Biotechnol. 2019; 47:3329-37. 7. Lemaitre M, Monsarrat P, BlascoBaque V, Loubières P, Burcelin R, Casteilla $L$, et al. Periodontal tissue regeneration using syngeneic adipose-derived stromal cells in a mouse model. Stem Cells Transl Med. 2017; 6:656-65. 8. Pellegrinelli V, Carobbio S, Vidal-Puig A. Adipose tissue plasticity: how fat depots respond differently to pathophysiological cues. Diabetologia. 2016; 59:1075-1088. 9. Zuk PA, Zhu M, Mizuno H, Huang J, Futrell JW, Katz AJ, et al. Multilineage cells from human adipose tissue: implications for cell-based therapies. Tissue Eng. 2001;7: 211-228. 10. Rangappa S, Fen C, Lee EH, Bongso A, Sim EK.

Transformation of adult mesenchymal stem cells isolated from the fatty tissue into cardiomyocytes. Ann Thorac Surg. 2003;75: 775-9. 11. Minteer DM, Marra KG, Rubin JP. Adipose stem cells: biology, safety, regulation, and regenerative potential. Clin Plast Surg.2015; 42:169-79. 12. Tobita M, Mizuno H. Periodontal disease and periodontal tissue regeneration. Curr Stem Cell Res Ther. 2010; 5:168-74. 13. Badimon L, Cubedo J. Adipose tissue depots and inflammation: effects on plasticity and resident mesenchymal stem cell function. Cardiovasc Res. 2017; 113:1064-73. 14. Zhao H, Shang Q, Pan Z, Bai Y, $\mathrm{Li} Z$, Zhang $\mathrm{H}$, et al. Exosomes from adipose-derived stem cells attenuate adipose inflammation and obesity through polarizing M2 macrophages and beiging in white adipose Tissue. Diabetes. 2018; 67:235-47. 15. Tobita M, Uysal AC, Ogawa R, Hyakusoku H, Mizuno H. Periodontal tissue regeneration with adipose-derived stem cells. Tissue Eng Part A. 2008; 14:945-53. 16. Wu PH, Chung HY, Wang JH, Shih JC, Kuo MY, Chang PC, et al. Amniotic membrane and adipose-derived stem cell co-culture system enhances bone regeneration in a rat periodontal defect model. J Formos Med Assoc. 2016; 115:186-94. 17. Huang Y, Zeng J, Chen G, Xie X, Guo W, Tian W. Periodontitis contributes to adipose tissue inflammation through the NF-B, JNK and ERK pathways to promote insulin resistance in a rat model. Microbes Infect. 2016; 18:804-12. 18. Lu Z, Wang G, Dunstan CR, Chen Y, Lu WY, Davies B, et al. Activation and promotion of adipose stem cells by tumour necrosis factor-alpha preconditioning for bone regeneration. J Cell Physiol. 2013; 228:1737-44. 19. Xu XC, Chen H, Zhang X, Zhai ZJ, Liu XQ, Zheng XY, et al. Effects of oestrogen deficiency on the alveolar bone of rats with experimental periodontitis. Mol Med Rep. 2015; 12:3494-502. 20. Huang Y, Guo W, Zeng J, Chen G, Sun W, Zhang X, et al. Prediabetes enhances periodontal inflammation consistent with activation of toll-like receptor-mediated nuclear factor-KB pathway in rats. J Periodontol. 2016; 87: e64-74. 21. Martins LG, Spreafico CS, Tanobe PG, Tavares TAA, Castro ML, Franco GCN, et al. Influence of adrenergic neuromodulation during induction of periodontitis in rats. J Int Acad Periodontol. 2017; 19:80-8. 22. Tozawa K, Ono-Uruga Y, Yazawa M, Mori T, Murata M, Okamoto S, et al. Mega karyocytes and platelets from a novel human adipose tissue-derived mesenchymal stem cell line. Blood. 2019;133: 633-43. 23. Lei G, Yan M, Wang Z, Yu Y, Tang C, Wang Z, et al. Dentinogenic capacity: immature root papilla stem cells versus mature root pulp stem cells. Biol Cell. 2011; 103:185-96. 24. Keller A, Rohde JF, Raymond K, Heitmann BL. Association between periodontal disease and overweight and obesity: a systematic review. J Periodontol. 2015; 86:766-76. 25. Stanko P, Izakovicova Holla L. Bidirectional association between diabetes mellitus and inflammatory periodontal disease. A review. Biomed Pap Med Fac Univ Palacky Olomouc Czech Repub. 2014; 158:35-8. 26. Abduljabbar T, Al-Sahaly F, Al-Kathami M, Afzal S, Vohra F. Comparison of periodontal and peri-implant 
inflammatory parameters among patients with prediabetes, type 2 diabetes mellitus and non-diabetic controls. Acta Odontol Scand. 2017; 75:319-24. 27. Zhang J, Zhang AM, Zhang ZM, Jia JL, Sui XX, Yu LR, et al. Efficacy of combined orthodontic-periodontic treatment for patients with periodontitis and its effect on inflammatory cytokines: A comparative study. Am J Orthod Dentofacial Orthop. 2017; 152:494-500. 28. Yoshimura A, Hara Y, Kaneko T, Kato I. Secretion of IL-1 beta, TNF-alpha, IL-8 and IL-1ra by human polymorphonuclear leukocytes in response to lipopolysaccharides from periodontopathic bacteria. $J$ Periodontal Res. 1997; 32:279-86. 29. Nishimura F, Iwamoto Y, Mineshiba J, Shimizu A, Soga Y, Murayama Y. Periodontal disease and diabetes mellitus: the role of tumor necrosis factor-alpha in a 2way relationship. J Periodontol. 2003; 74:97-102. 30. Tzanavari T, Giannogonas P, Karalis KP. TNF-alpha and obesity. Curr Dir Autoimmun. 2010; 11:145-56. 31. Venkataiah VS, Handa K, Njuguna MM, Hasegawa T, Maruyama K, Nemoto E, et al. Periodontal regeneration by allogeneic transplantation of adipose tissue derived multi-lineage progenitor stem cells in vivo. Sci Rep.2019;9:921. 32. Zhang J, Chen J. Bone tissue regeneration - application of mesenchymal stem cells and cellular and molecular mechanisms. Curr Stem Cell Res Ther. 2017; 12:357-64. 33. Hassan WU, Greiser U, Wang W. Role of adipose-derived stem cells in wound healing. Wound Repair Regen. 2014; 22:313-25. 34. Sukho P, Kirpensteijn J, Hesselink JW, van Osch GJ, Verseijden F, Bastiaansen-Jenniskens YM. Effect of cell seeding density and inflammatory cytokines on adipose tissue-derived stem cells: an in vitro study. Stem Cell Rev. 2017; 13:267-77. 35. Park JC, Kim JM, Jung IH, Kim JC, Choi SH, Cho KS, et al. Isolation and characterization of human periodontal ligament (PDL) stem cells (PDLSCs) from the inflamed PDL tissue: in vitro and in vivo evaluations. J Clin Periodontol. 2011; 38: 721-31. 36. Tang HN, Xia Y, Yu Y, Wu RX, Gao LN, Chen FM. Stem cells derived from "inflamed" and healthy periodontal ligament tissues and their sheet functionalities: a patientmatched comparison. J Clin Periodontol. 2016; 43:72-84. 37. Yu B, Li Q, Zhou M. LPS-induced upregulation of the TLR4 signaling pathway inhibits osteogenic differentiation of human periodontal ligament stem cells under inflammatory conditions. Int J Mol Med. 2019; 43:2341-51. 38. Xu XY, He XT, Wang J, Li X, Xia Y, Tan YZ, et al. Role of the P2X7 receptor in inflammation-mediated changes in the osteogenesis of periodontal ligament stem cells. Cell Death Dis. 2019; 10:20. 39. Wlodarski KH, Reddi AH. Alkaline phosphatase as a marker of osteoinductive cells. Calcif Tissue Int. 1986; 39:382-5. 40. Stein GS, Lian JB, van Wijnen AJ, Stein JL, Montecino M, Javed A, et al. Runx2 control of organization, assembly and activity of the regulatory machinery for skeletal gene expression.Oncogene.2004; 23:4315-29. 41. Rosen V. BMP2 signaling in bone development and repair. Cytokine Growth Factor Rev. 2009; 20: 475-80.

\section{Tables}

Table 1 Sequences of primers 


\begin{tabular}{|c|c|}
\hline Genes & Sequences of primers \\
\hline GAPDH & F: 5'-TATGACTCTACCCACGGCAAG-3' R:5'-TACTCAGCACCAGCATCACC-3' \\
\hline ALP & F: 5'-CGTTGACTGGTTACTGCTGA-3' R:5'-CTTCTTGTCCGTGTCGCTCAC -3' \\
\hline BMP2 & F:5'-GACATCCACTCCACAAACGAGA-3' \\
& R:5'-GTCATTCCACCCCACATCACT-3' \\
\hline Runx2 & F:5'-GAGCACAAACATGGCTGAGA-3' \\
& R:5'-TGGAGATGTTGCTCTGTTCG-3' \\
\hline TNF- $\alpha$ & F: 5'-ACTCCCAGAAAAGCAAGCAA-3' \\
& R:5'-CGAGCAGGAATGAGAAGAGG-3' \\
\hline IL-1ß & F: 5'-GGGATGATGACGACCTGCTA-3' \\
& R:5'-TGTCGTTGCTTGTCTCTCCT-3' \\
\hline TLR4 & F: 5'-TTATCCAGAGCCGTTGGTGT-3' \\
& R:5'-CCCACTCGAGGTAGGTGTTT-3' \\
\hline
\end{tabular}

\section{Figures}

\section{Figure 1}

Experiment periodontitis inhibited the levels of TNF- $\alpha$, IL-1 $\beta$ and TLR4 in adipose tissue. (A) Representative rat maxilla showing the alveolar bone loss by image and the quantitative data of vertical alveolar bone loss between CEJ and ABC in mm.(B)The expression of TNF-a, IL-1 $\beta$ and TLR4 was stained using specific antibodies and hematoxylin. (C) The gene levels of TNF- $a$ and IL-1 $\beta$ in adipose tissue. Results are mean \pm SEM. ${ }^{\star} \mathrm{P}<0.05,{ }^{\star *} \mathrm{P}<0.001$ versus Con group. 

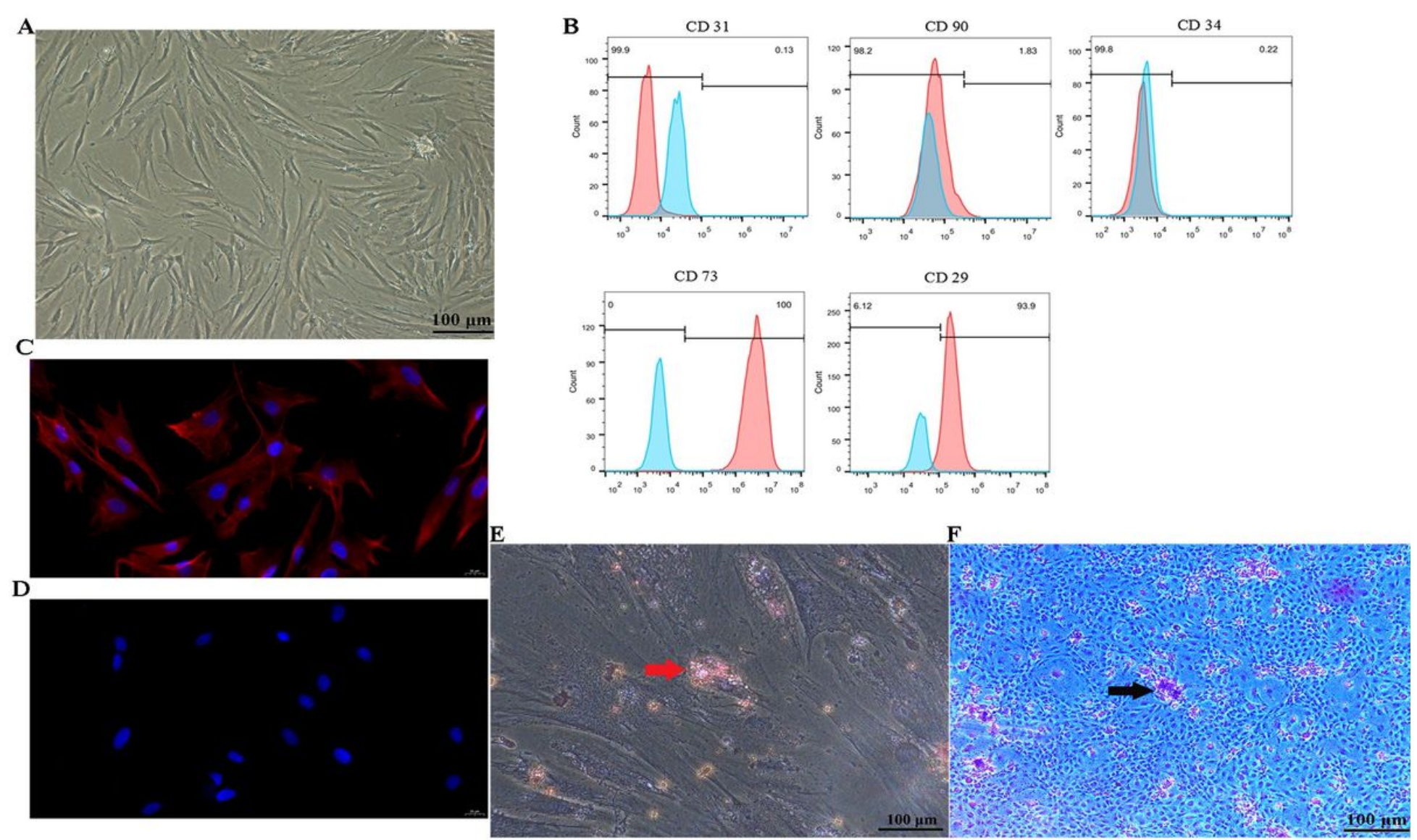

Figure 2

ASCs characteristics assay. (A) The morphology of ASCs. (B) Flow cytometry analysis showed that ASCs expressed CD73 and CD29, did not express CD31, CD90 and, CD34. (C) Cells was stained with Vimentin. (D) Cells were stained with CK-14. (E) Cells cultured in osteogenic induction medium for 4 weeks, Stained with Alizarin Red. (F) Cells cultured in adipogenic induction medium for 2 weeks, Stained with Oil Red O. 


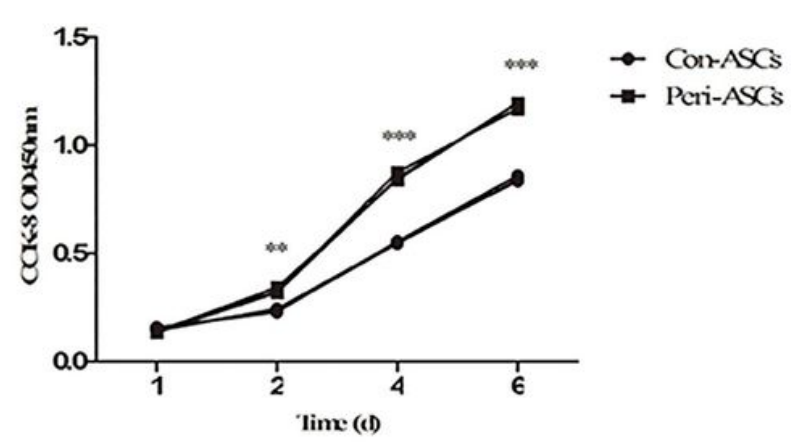

Od
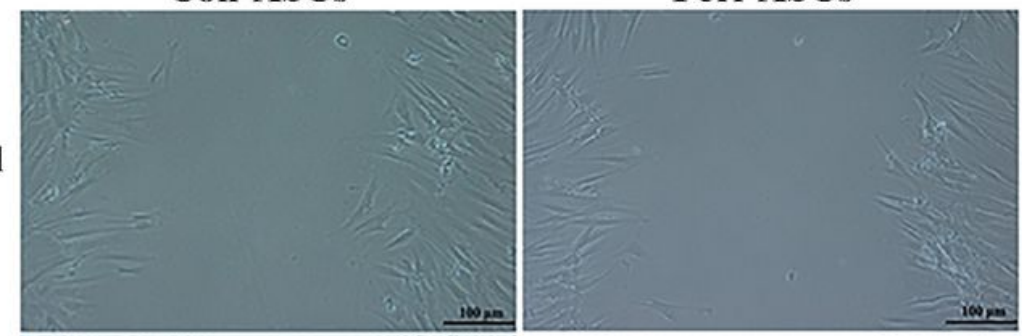

1d
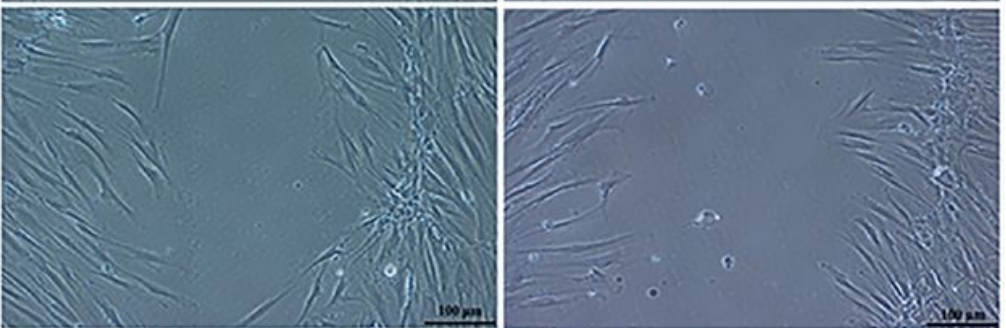

C

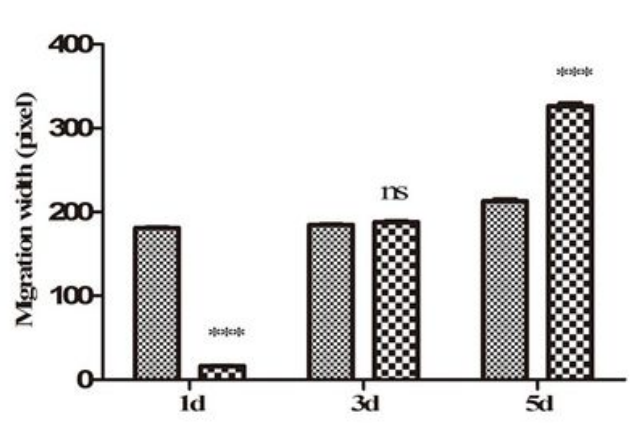

3d

Con-ASCs

$\infty$ Peri-ASCS
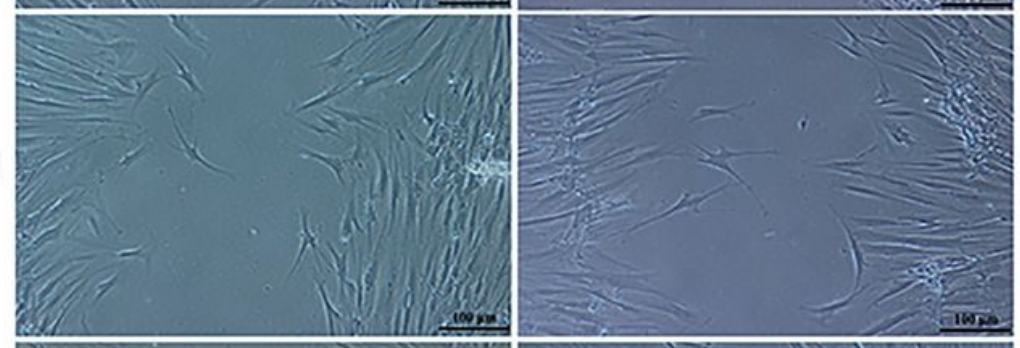

5d

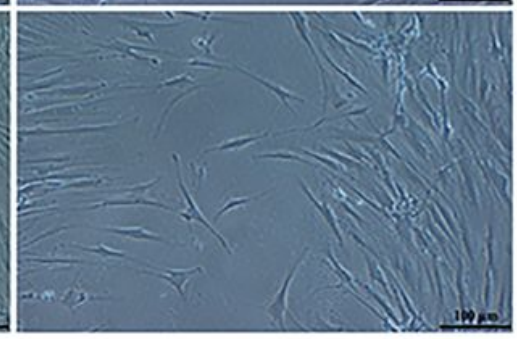

\section{Figure 3}

Experiment periodontitis increased the proliferation and wound-healing migration of ASCs. (A) The growth cure of ASCs in two groups. (B) Representative images and quantification from two separate experiments of wound healing assays. (C) The value OD data were presented as the mean \pm SEM. of three independent experiments. $d$, day; ${ }^{\star} P<0.05, \star \star P<0.01$ compared with negative control and $0 \mathrm{~d}$ of preconditioning.

\section{Figure 4}

Periodontitis inhibited the gene expression of ALP and BMP2, while increased the Runx2 gene expression in osteogenic medium for 3, 5, 7 days. (A) The ALP gene levels. (B) The Runx2 gene levels. (C) The BMP2 gene levels. (D) ALP activity at 3-day, 5-day and 7-day after osteogenic medium culture. Data are expressed as the mean \pm SEM over three slides. $d$, day; $P<0.05 ; * \star P<0.01 ; * \star \star ~ P<0.001$ compared to the Con-ASCs. 
Figure 5

Effects of experiment periodontitis on protein expression of ALP, Runx2 and BMP2 after 3-day, 5-day and 7-day simulation. A and B, Western blot results and quantitative data of ALP, Runx2 and BMP2 in ConASCs group and Peri-ASCs group. Data are expressed as the mean \pm SEM over three slides. $d$, day; * $P<$ $0.05 ;{ }^{* *} \mathrm{P}<0.01 ; * \star * \mathrm{P}<0.001$ compared to the Con-ASCs. 